\title{
THE ULTRASTRUCTURAL LOCALIZATION OF $\alpha$-BUNGAROTOXIN BINDING SITES IN RELATION TO SYNAPSES ON CHICK CILIARY GANGLION NEURONS ${ }^{1}$
}

\author{
MICHELE H. JACOB AND DARWIN K. BERG ${ }^{2}$ \\ Department of Biology, University of California, San Diego, La Jolla, California 92093 \\ Received May 21, 1982; Revised August 16, 1982; Accepted August 24, 1982
}

\begin{abstract}
The distribution of $\alpha$-bungarotoxin binding sites on chick ciliary ganglion neurons was examined at the ultrastructural level by incubating ganglia with horseradish peroxidase-conjugated toxin and examining the peroxidase-stained and thin-sectioned ganglia with the electron microscope. Both in embryonic and in adult ganglia heavy labeling was restricted to the surface membrane of short processes emerging from the ciliary and choroid cell somata in the region of preganglionic innervation. Less dense labeling occasionally was present on the smooth surface membrane of the soma in the same region. In contrast, the pre- and postsynaptic membranes of most synapses were clearly not labeled even in the immediate vicinity of heavily labeled processes. The labeling represented specific binding of the toxin conjugate since it could be prevented by $d$-tubocurarine and hexamethonium or by unconjugated toxin. The conjugated toxin was not excluded from the synaptic cleft on the basis of size because a substantially larger protein conjugate, a horseradish peroxidase-labeled monoclonal antibody, was able to enter the cleft and heavily label synaptic membranes as well as soma membranes. Even neurons in adult ganglia had very little synaptic labeling after exposure to the conjugated toxin. These results strongly suggest that the high affinity $\alpha$-bungarotoxin binding sites on chick ciliary ganglion neurons are different from the synaptic ACh receptors which would be expected to be concentrated in the postsynaptic membrane. Clustering of the $\alpha$-bungarotoxin binding sites in the vicinity of synapses, however, may reflect a related synaptic function.
\end{abstract}

A continuing controversy exists as to whether $\alpha$-bungarotoxin $(\alpha$-Bgt) binds to neuronal nicotinic acetylcholine $(\mathrm{ACh})$ receptors as it does to $\mathrm{ACh}$ receptors in skeletal muscle and electric tissue. High affinity saturable binding of $\alpha$-Bgt has been reported for a number of neural tissues receiving cholinergic input in both vertebrates and invertebrates (recently reviewed by Morley and Kemp, 1981; Oswald and Freeman, 1981). In these cases the binding of $\alpha$-Bgt was shown to be competitively inhibited by nicotinic agonists and antagonists. Ultrastructural studies using horseradish peroxidase-labeled

\footnotetext{
${ }^{1}$ This work was supported by National Institutes of Health Grant NS 12601 and by grants from the Muscular Dystrophy Association and the American Heart Association with funds contributed in part by the California Heart Association. We thank Dr. Douglas Fambrough and Jennifer L. Schwartz of the Carnegie Institution of Washington for the generous gift of horseradish peroxidase-labeled monoclonal antibody against a neuronal surface membrane component. We thank Alfredo Franco, Jr. for skilled technical assistance with the preparation of the figures, and we thank Dr. Nicholas Spitzer and Dr. Janet Lamborghini for reviewing this manuscript. M. H. J. is a fellow of the Muscular Dystrophy Association of America.

${ }^{2}$ To whom correspondence should be addressed.
}

$\alpha$-Bgt (HRP-Bgt) or $\left[{ }^{125} \mathrm{I}\right] \alpha$-Bgt generally have been interpreted as revealing preferential binding of the toxin in the vicinity of synapses and in some cases as being specifically associated with postsynaptic membranes (Lentz and Chester, 1977; Vogel et al., 1977; Arimatsu et al., 1978; Hunt and Schmidt, 1978; Schwartz and Bok, 1979; Marshall, 1981).

The relationship of the $\alpha$-Bgt binding site to the nicotinic ACh receptor, however, remains unclear. Antibody prepared against eel $\mathrm{ACh}$ receptor has been found to be incapable of recognizing $\alpha$-Bgt binding sites on $\mathrm{PC} 12$ cells, a rat pheochromocytoma cell line, even though it does inhibit the function of PC12 ACh receptors (Patrick and Stallcup, 1977a). Furthermore, many investigators have reported that concentrations of $\alpha$-Bgt adequate to saturate high affinity binding sites on a variety of autonomic and central neurons of higher vertebrates fail to have any delectable effect on the physiological function of ACh receptors on the cells (Nurse and O'Lague, 1975; Duggan et al., 1976; Ko et al., 1976; Brown and Fumagalli, 1977; Bursztajn and Gershon, 1977; Patrick and Stallcup, 1977b; Carbonetto et al., 1978; Kouvelas et al., 1978; Ascher et al., 1979; Betz, 1981). Exceptions include the 
retinotectal projection of several vertebrate species (Oswald and Freeman, 1981), the paravertebral sympathetic ganglion of the adult bullfrog (Marshall, 1981), and the human medulloblastoma cell line TE671 (Syapin et al., 1982), where $\alpha$-Bgt has been reported to block ACh receptor function.

The chick ciliary ganglion is a useful preparation for examining the relationship between nicotinic ACh receptors and $\alpha$-Bgt binding sites on neurons. The ganglion contains two populations of neurons: ciliary and choroid cells. The only known chemical synapses on the cells are nicotinic cholinergic and represent preganglionic input from the accessory oculomotor nucleus (Martin and Pilar, 1963a, b; Cowan and Wenger, 1968; Landmesser and Pilar, 1978). All of the neurons in the ganglion receive functional synaptic input as early as embryonic day 7 (Landmesser and Pilar, 1974a). The neurons also have high affinity $\alpha$-Bgt binding sites (Chiappinelli and Giacobini, 1978; Fumagalli et al., 1978), but occupation of the sites with $\alpha$-Bgt does not block ACh receptor function (Ravdin and Berg, 1979; Chiappinelli et al., 1981; Margiotta and Berg, 1982). Either of two minor protein toxins (Bgt 3.1 or Bgt 3.3) present in the venom of Bungarus multicinctus can reversibly block the ACh sensitivity, and each can be separated chromatographically from the well known $\alpha$-Bgt (also referred to as Bgt 2.2) (Ravdin and Berg, 1979). Since Bgt 3.1 can block ACh sensitivity even when the $\alpha$-Bgt sites are occupied with $\alpha$-Bgt, it was concluded that the neurons must have at least two classes of toxin binding sites, one being the high affinity $\alpha$-Bgt site and the other being a site related to $\mathrm{ACh}$ receptor function which is recognized by Bgt 3.1 but not by $\alpha$-Bgt (Ravdin et al., 1981). It was not clear whether the two classes of sites were present on the same macromolecule or on different macromolecules.

The present study was undertaken to examine with ultrastructural techniques the distribution of $\alpha$-Bgt binding sites on the surfaces of ciliary ganglion neurons in order to determine whether high levels of $\alpha$-Bgt binding

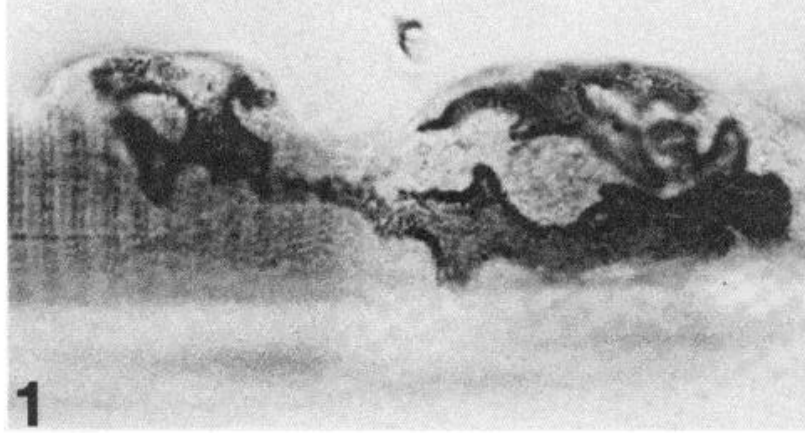

Figure 1. Binding of HRP-Bgt to the vertebrate neuromuscular junction. A freshly dissected soleus muscle from a 1month-old mouse was incubated in $0.1 \mathrm{M}$ sodium phosphate buffer, $\mathrm{pH} 7.2$, containing $10^{-7} \mathrm{M}$ HRP-Bgt for $1 \mathrm{hr}$ at room temperature, rinsed for $2 \mathrm{hr}$ with several changes of $0.1 \mathrm{M}$ sodium cacodylate buffer, $\mathrm{pH} 7.2$, fixed, rinsed, and stained for peroxidase activity. Single muscle fibers were teased out, mounted on glass slides, and photographed through a light microscope. Magnification $\times 3640$.

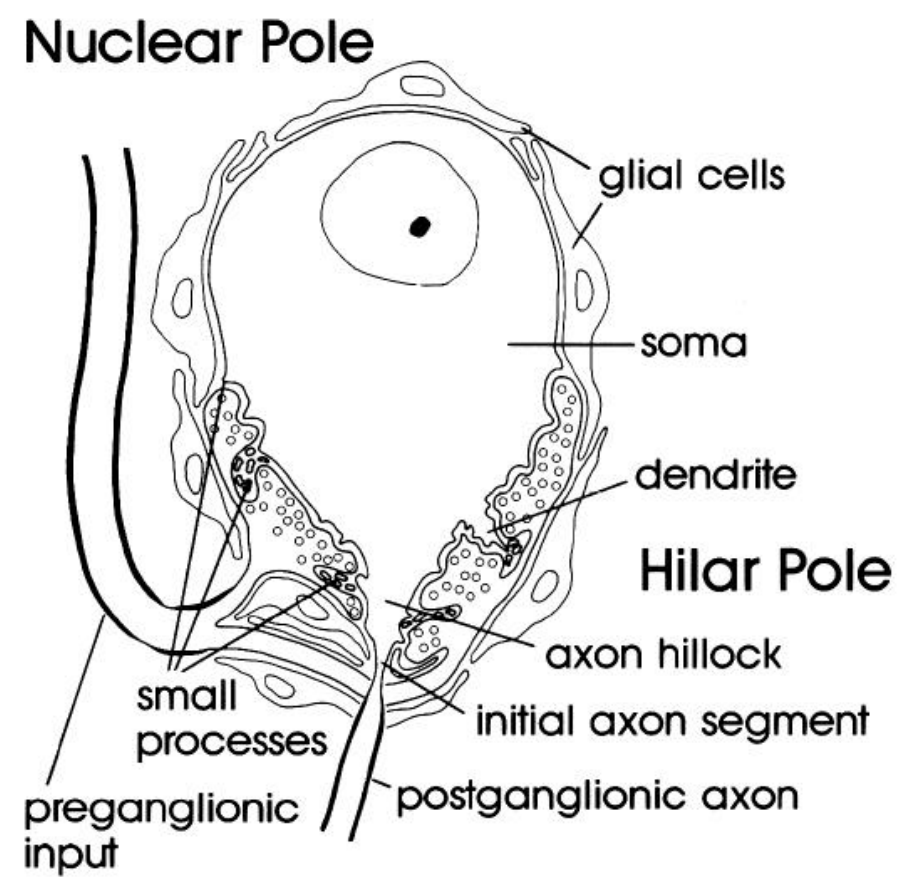

Figure 2. Schematic representation of a ciliary neuron from a 16-day-old chick embryo. Presynaptic inputs from the accessory oculomotor nucleus form a calyx which covers a large portion of the ciliary cell soma in the hilar region. In addition, there is a series of synaptic boutons contacting the membrane of the axon hillock. Numerous short evaginations or processes characterize the surface of the soma, dendrites, and axon hillock in the region of preganglionic innervation. The diagram is based on original micrographs and on the figures of Landmesser and Pilar (1974b) and Cantino and Mugnaini (1975).

are found on the postsynaptic membrane as would be expected if the site were associated with the synaptic ACh receptor.

\section{Materials and Methods}

Preparation of horseradish peroxidase-labeled $\alpha$ bungarotoxin. $\alpha$-Bungarotoxin ( $\alpha$-Bgt) was purified from Bungarus multicinctus venom as described previously (Ravdin and Berg, 1979). Horseradish peroxidase was conjugated to the purified $\alpha$-Bgt by a modification (Lentz et al., 1977) of the procedure described by Nakane and Kawaoi (1974). The conjugated horseradish peroxidase$\alpha$-bungarotoxin (HRP-Bgt) was fractionated by gel filtration through Ultrogel AcA44, and material in the size range of 40,000 to 70,000 daltons was pooled and used for the studies reported here. HRP-Bgt monoconjugate has a size of about 48,000 daltons. Unconjugated $\alpha$-Bgt $(8,000$ daltons) and conjugates containing more than one molecule of HRP ( $\geq 88,000$ daltons) were removed by the fractionation.

The purified HRP-Bgt specifically labeled the end plate region of a mouse soleus muscle fiber as expected for $\alpha$-Bgt derivatives which bind to skeletal muscle ACh receptors (Fig. 1).

Tissue incubation and cytochemistry. Ciliary ganglia from 14-, 16-, and 20-day-old White Leghorn chick embryos and 8-month-old chickens were dissected and pinned out in aerated $\left(95 \% \mathrm{O}_{2}, 5 \% \mathrm{CO}_{2}\right)$ avian Ringer solution (Ginsborg, 1960) in Sylgard-coated Petri dishes. 
The tissue was incubated in $10^{-7}$ м HRP-Bgt for $2 \mathrm{hr}$ at room temperature with gentle agitation and aeration. Ganglia then were rinsed with Ringer solution for $2 \mathrm{hr}$, fixed in $2 \%$ formaldehyde and $2 \%$ glutaraldehyde for 1 $\mathrm{hr}$, rinsed, reacted for peroxidase activity, rinsed, postfixed, and processed for electron microscopy as described previously (Jacob and Lentz, 1979) except that $0.1 \mathrm{M}$ sodium phosphate ( $\mathrm{pH} 7.2$ ) was used throughout as the buffer. Thin sections were stained lightly with methanolic uranyl acetate and examined with a Phillips 300 electron microscope.

Reagents. Bungarus multicinctus venom was purchased from Miami Serpentarium. Horseradish peroxidase (type VI), $d$-tubocurarine, and hexamethonium were obtained from Sigma Chemical Co. Horseradish peroxidase-labeled monoclonal antibody to a neuronal surface membrane component was kindly provided by Dr. Doug- las Fambrough and Jennifer L. Schwartz of the Carnegie Institution of Washington.

\section{Results}

\section{Morphological features}

Ciliary neurons. The cytological features and synaptic morphologies of ciliary and choroid neurons are summarized here to provide a background for interpreting the distribution of HRP-Bgt binding on the cells. The ciliary cell has a large ovoid soma and an eccentrically located nucleus (Fig. 2). The Nissl substance is distributed in a perinuclear ring, while the cell periphery is characterized by a light cytoplasm. The region of the cell containing the nucleus is termed the nuclear pole and is delimited by a smooth surface membrane covered by a glial cell sheath. The opposite end, the hilar pole, is the region from which the axon emerges, and this area re-
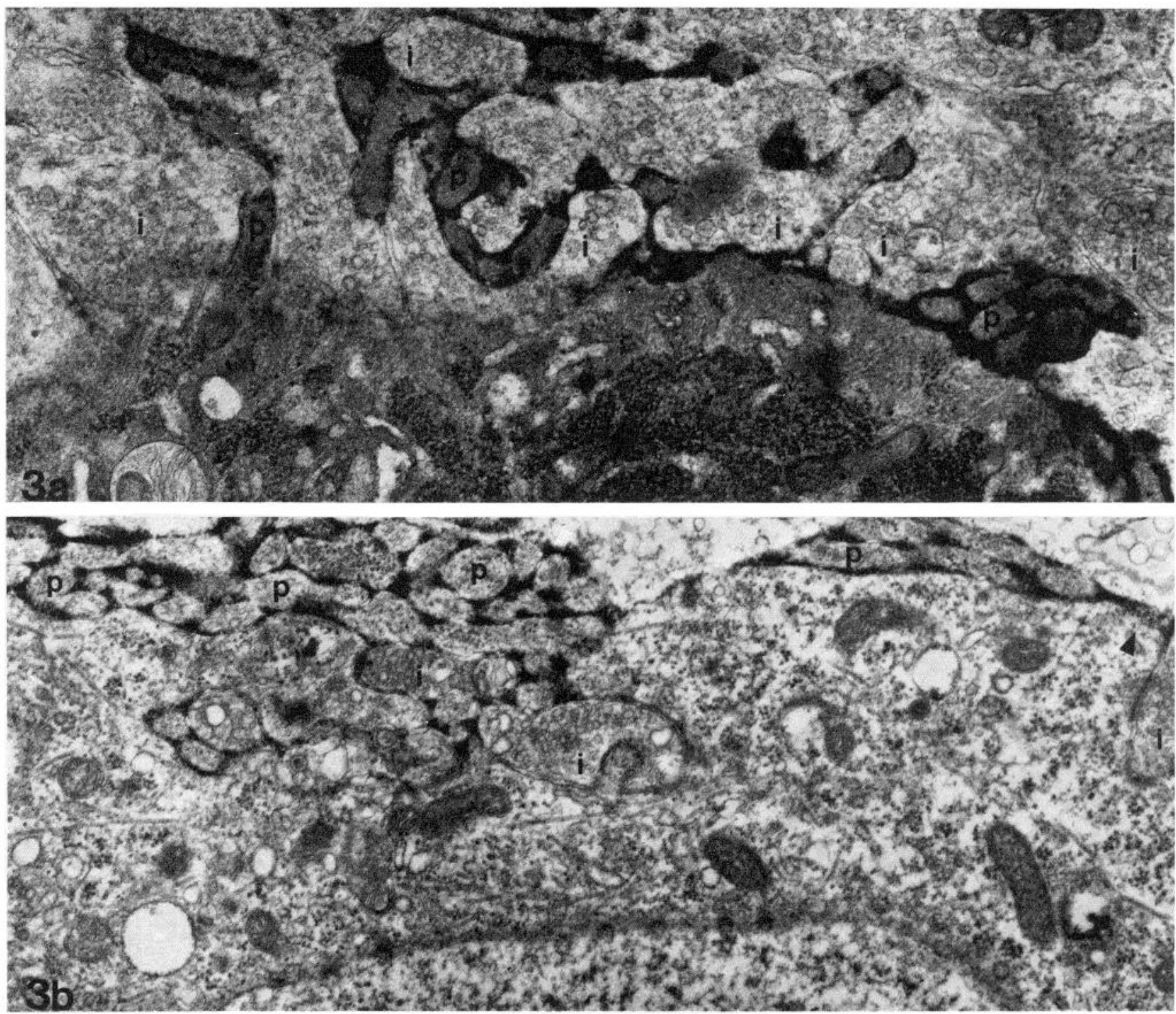

Figure 3. Binding of HRP-Bgt to the embryonic neuron surface. A choroid neuron from a 14-day-old $(a)$ and a ciliary neuron from a 16-day-old $(b)$ chick embryo are heavily labeled on the surface of the numerous short processes $(p)$ emerging from the soma in the region of preganglionic innervation $(i)$ following incubation in $10^{-7} \mathrm{M} \mathrm{HRP}-\mathrm{Bgt}$ and HRP reaction. Less dense labeling occasionally is present on the smooth surface membrane in the vicinity of the heavily labeled processes (arrowhead). a, Magnification $\times 105,490 ; b$, magnification $\times 67,090$. 

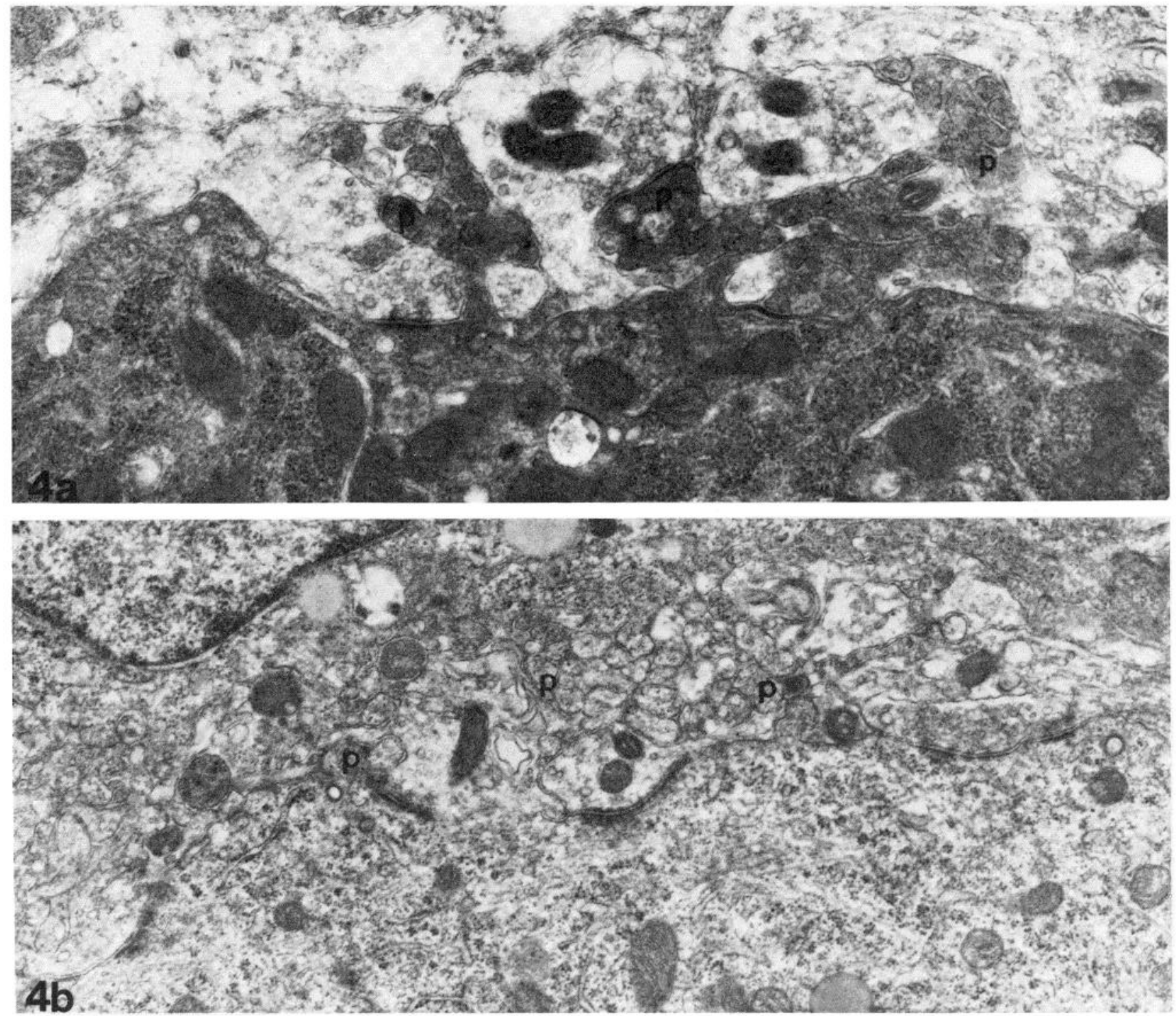

Figure 4. Specificity of HRP-Bgt binding to the embryonic neuron surface. $a$, The short processes $(p)$ and smooth surface membrane of a 16-day-old chick embryo choroid neuron are not labeled following incubation in $100 \mu \mathrm{M} d$-tubocurarine and 1.4 $\mathrm{mM}$ hexamethonium prior to and along with $10^{-7} \mathrm{HRP}-\mathrm{Bgt}$. Magnification $\times 58,430$. $b$, Similarly, reaction product is not present on the short processes $(p)$ or smooth surface membrane of a 16-day-old chick embryo ciliary neuron following incubation in $10^{-5}$ M Bgt prior to and along with $10^{-7}$ M HRP-Bgt. Magnification $\times 53,380$.

ceives the preganglionic inputs from the accessory oculomotor nucleus (Martin and Pilar, 1963a, b; Cowan and Wenger, 1968; Landmesser and Pilar, 1978). The incoming presynaptic fibers to the ciliary cells undergo a series of developmental transformations. Initially, multiple synaptic contacts are established early in development. By stage 39 (14 days in ovo) the synaptic boutons reorganize to form a calyx which covers a large portion of the soma in the hilar region. At hatching and continuing for several months afterward, the calyx breaks up into numerous synaptic boutons (Hess, 1965; Landmesser and Pilar, $1972,1974 \mathrm{~b}, 1978)$. In the region of the axon hillock a series of synaptic boutons can be found in contact with the surface membrane throughout this period. Several short evaginations or processes extend from the surface of the ciliary cell soma, dendrites, and axon hillock in the region of preganglionic innervation and are present throughout development. In the adult avian ciliary ganglion, these processes are known to represent the most richly innervated region of the neuron surface (Cantino and Mugnaini, 1975).

Choroid neurons. The choroid cell has a small spherical soma, a centrally located nucleus, and a characteristic dense cytoplasm containing numerous free ribosomes, polysomes, and Nissl bodies. The incoming presynaptic fibers form multiple synaptic contacts on the choroid cell surface which remain as individual boutons (Hess, 1965; Landmesser and Pilar, 1972, 1974b). Several short processes emerge from the choroid cell soma in the vicinity of the presynaptic terminals. 


\section{HRP-Bgt binding in embryonic tissue}

Neuronal processes. When ciliary ganglia from 14-, 16-, and 20-day-old chick embryos were incubated in $10^{-7}$ M HRP-Bgt and reacted for HRP, heavy labeling was associated with most of the short processes emerging from the nerve cell surfaces in the region of preganglionic innervation (Fig. 3). Less dense labeling occasionally was present on the smooth surface membrane of the soma in adjacent regions.

The binding of HRP-Bgt to the surface of embryonic ciliary ganglion neurons was specific since it was blocked by cholinergic antagonists. Incubation of the ganglia in $100 \mu \mathrm{M} d$-tubocurarine and $1.4 \mathrm{~mm}$ hexamethonium prior to and along with $10^{-7} \mathrm{M}$ HRP-Bgt completely prevented the labeling (Fig. 4). Labeling of the neurons also was prevented by incubating the ganglia in $10^{-5} \mathrm{M}$ Bgt prior to and along with $10^{-7} \mathrm{M}$ HRP-Bgt, demonstrating that native toxin competes with the conjugated toxin for binding sites and that the sites are saturable (Fig. 4).

Synapses. The pre- and postsynaptic membranes of nearly all clearly identifiable synapses in embryonic ganglia were unlabeled by HRP-Bgt even though heavily labeled structures were found in the immediate vicinity of the unlabeled synapses (Fig. 5). Synapses on ciliary ganglion neurons are characterized by a strictly parallel arrangement and thickening of the pre- and postsynaptic membranes, a widening of the cleft, an enhanced postsynaptic density, and an accumulation of clear synaptic vesicles adjacent to the presynaptic membrane (De Lorenzo, 1960; Hess, 1965; Landmesser and Pilar, 1972). Unlabeled synapses were present on the smooth portion of the cell surface and on the short processes emerging from the soma, dendrites, and axon hillock in the region of preganglionic innervation (Fig. 5). Short processes in the immediate vicinity of the unreacted synapses often were heavily labeled. Close juxtaposition of labeled surface membrane and unlabeled synapses was apparent; the layer of reaction product coating the nonsynaptic portion of the surface membrane did not extend into the specialized synaptic zone.

Access of HRP-Bgt. The absence of reaction product in the synapse is unlikely to reflect an inability of the conjugated toxin to penetrate into the specialized zone. Unconjugated HRP, which is nearly as large as the conjugated toxin, was able to penetrate the spaces separating the presynaptic terminals and the postsynaptic neurons. In some cases, HRP preferentially filled the widened synaptic cleft separating the pre- and postsynaptic membranes while only sparsely outlining the remaining intercellular spaces (Fig. 6).

Figure 5. Absence of HRP-Bgt labeling at synapses on embryonic neurons. The pre- and postsynaptic membranes of synapses on the somata of 14- $(a), 16-(b)$ and 20-day-old $(c)$ chick embryo ciliary neurons are not labeled following HRPBgt incubation and HRP reaction. The synapses (arrows) are characterized by a strictly parallel arrangement and thickening of the pre- and postsynaptic membranes, a widening of the cleft, an enhanced postsynaptic density, and an accumulation of clear synaptic vesicles adjacent to the presynaptic membrane. Short processes $(p)$ in the immediate vicinity of the unreacted synapses are heavily labeled. $a$, Magnification $\times 84,160 ; b$, magnification $\times 63,480 ; c$, magnification $\times 68,770$.
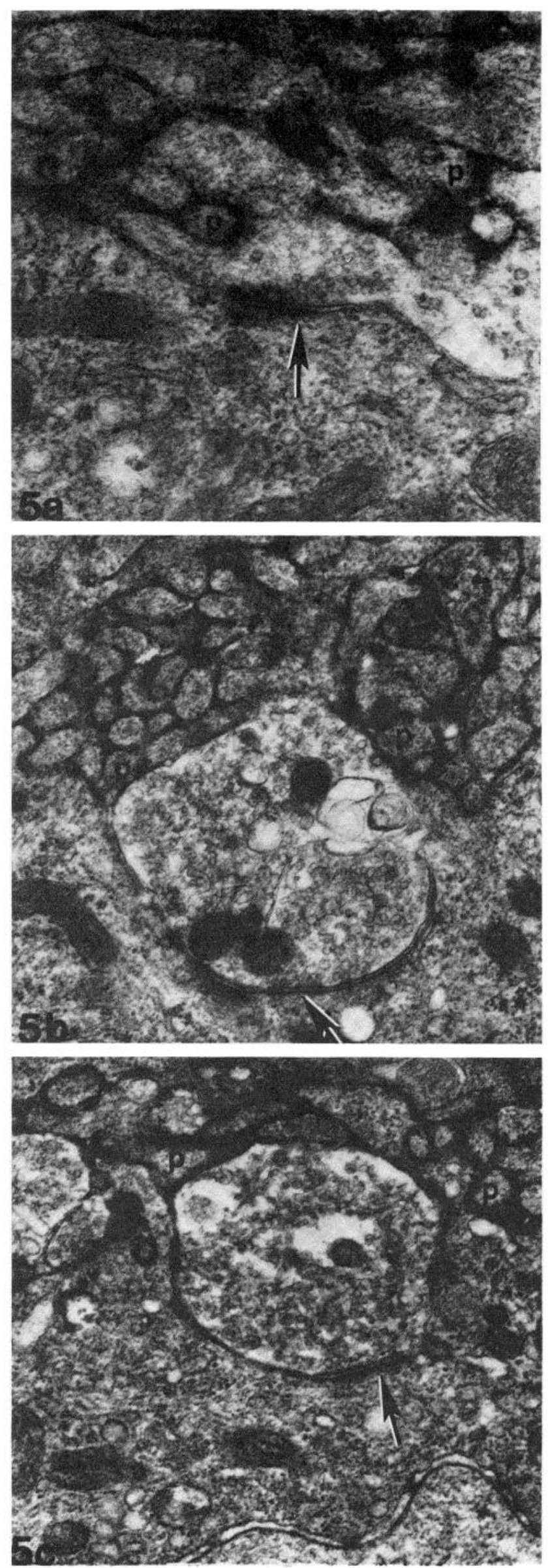


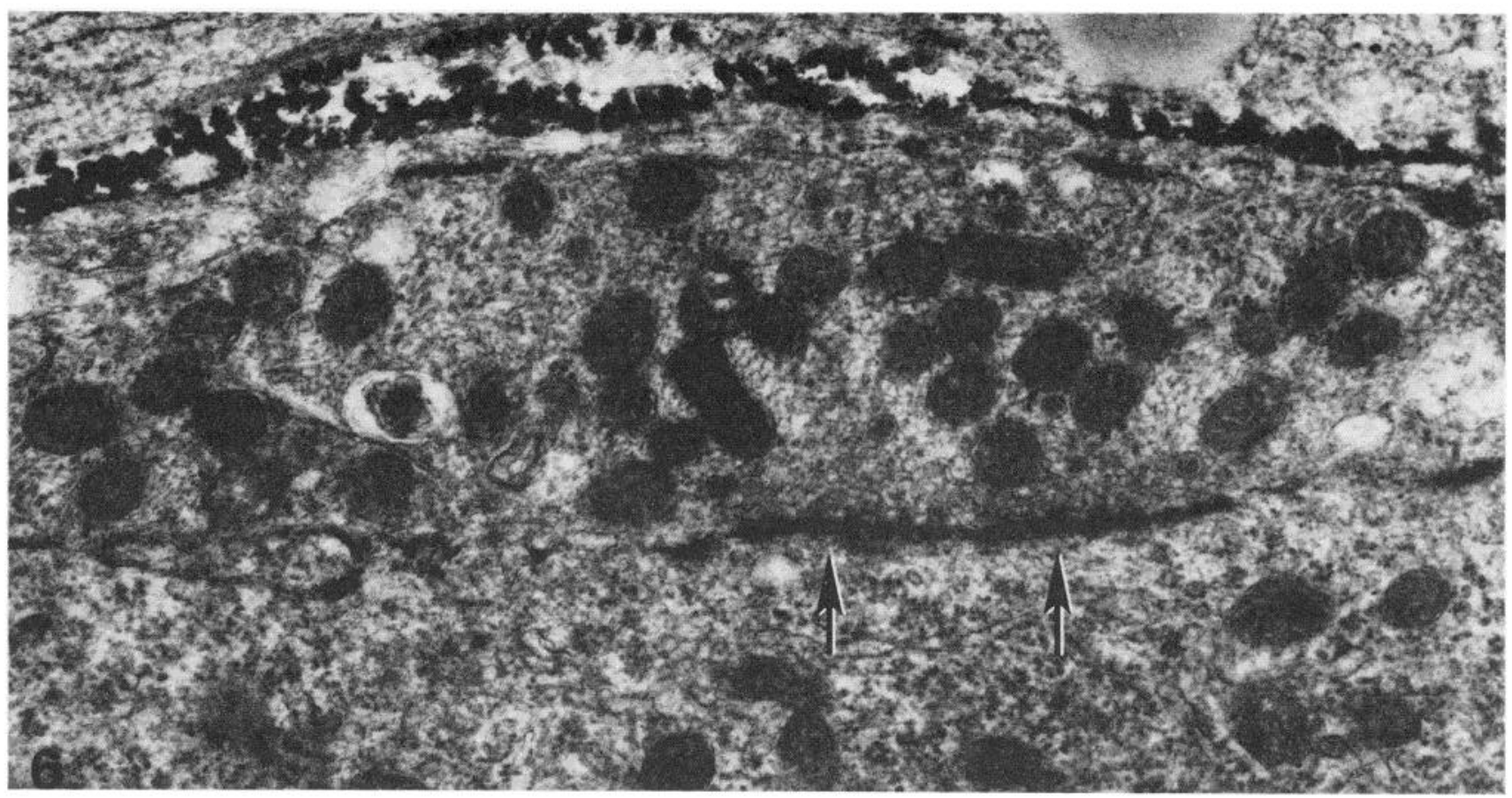

Figure 6. Accessibility of the synaptic membranes to HRP. The cleft of a synapse (arrows) on the soma of a 16-day-old chick embryo ciliary neuror is completely filled with HRP reaction product following incubation of the ganglion in avian Ringer solution containing $10^{-6} \mathrm{M} \mathrm{HRP}$ for $2 \mathrm{hr}$ at room temperature, fixation without prior washing, rinsing, and staining for peroxidase activity. Magnification $\times 87,530$.

An HRP-labeled monoclonal antibody to a neuronal surface membrane component (kindly provided by Dr. Douglas Fambrough and Jennifer L. Schwartz of the Carnegie Institution of Washington) was also able to penetrate and label the synaptic areas (Fig. $7 a$ ). In addition, incubation in the HRP-labeled monoclonal antibody followed by HRP reaction led to labeling of entire ciliary and choroid neuron surface membranes (Fig. 7b). Since the HRP-labeled antibody is about 4 times as large as HRP-Bgt, the conjugated toxin clearly should have had access to the synapse. Furthermore, the labeling pattern obtained with the antibody confirms that the techniques routinely used to wash, fix, and process the tissue would not have selectively removed HRP reaction product from the synaptic area.

\section{HRP-Bgt binding in adult tissue}

The distribution of HRP-Bgt binding sites on neurons in 8-month-old chick ciliary ganglia is similar to that found in embryonic tissue. The pre- and postsynaptic membranes usually did not have any deposits of HRPBgt reaction product, while heavy labeling coated the surface membranes of short processes emerging from the ciliary cell somata immediately adjacent to the unlabeled specialized synaptic zones (Figs. 8 and 9). Other short processes extending from the cell surface in the region of preganglionic innervation were also lined by reaction product. Less dense labeling occasionally was present on small areas of the smooth surface membrane in the vicinity of the unreacted synapses (Fig. 8). By 8 months of age the preganglionic innervation of the ciliary cell population has undergone its complete series of developmental transformations and attained a mature adult state. It seems appropriate to conclude, then, that most mature synapses on the neurons clearly lack HRP-Bgt labeling as do nearly all developing synapses.

The presence of reaction product on the short processes and smooth surface membrane of neurons in 8month-old ciliary ganglia represents specific binding of HRP-Bgt since no labeling was observed when the cholinergic antagonists $d$-tubocurarine and hexamethonium were included in the incubation media prior to and along with HRP-Bgt (Fig. 10).

\section{Quantitation of unlabeled synapses}

Although most synapses in embryonic and adult ganglia were unlabeled following HRP-Bgt incubation and HRP reaction, a small number were lightly labeled. To determine the proportion of synapses on the neurons that were either unlabeled or lightly labeled, cells were selected which had at least some HRP-Bgt labeling on their surface to ensure that the HRP-Bgt did penetrate the ganglion in the region occupied by the cells. Clearly identifiable synapses then were distinguished and scored as unlabeled, lightly labeled, or heavily labeled (Table I). Synapses were considered unlabeled when there was no reaction product present on the pre- or postsynaptic membranes or within the synaptic cleft. The designation lightly labeled was used for synapses containing a variable but small number of globular deposits of reaction product irregularly lining the postsynaptic membrane (Fig. 11). The label was less dense, uneven, and more punctate than the layer of reaction product that was observed coating the surface membrane of the short processes in the vicinity of the synapse. The category heavily labeled was used to indicate levels of reaction 

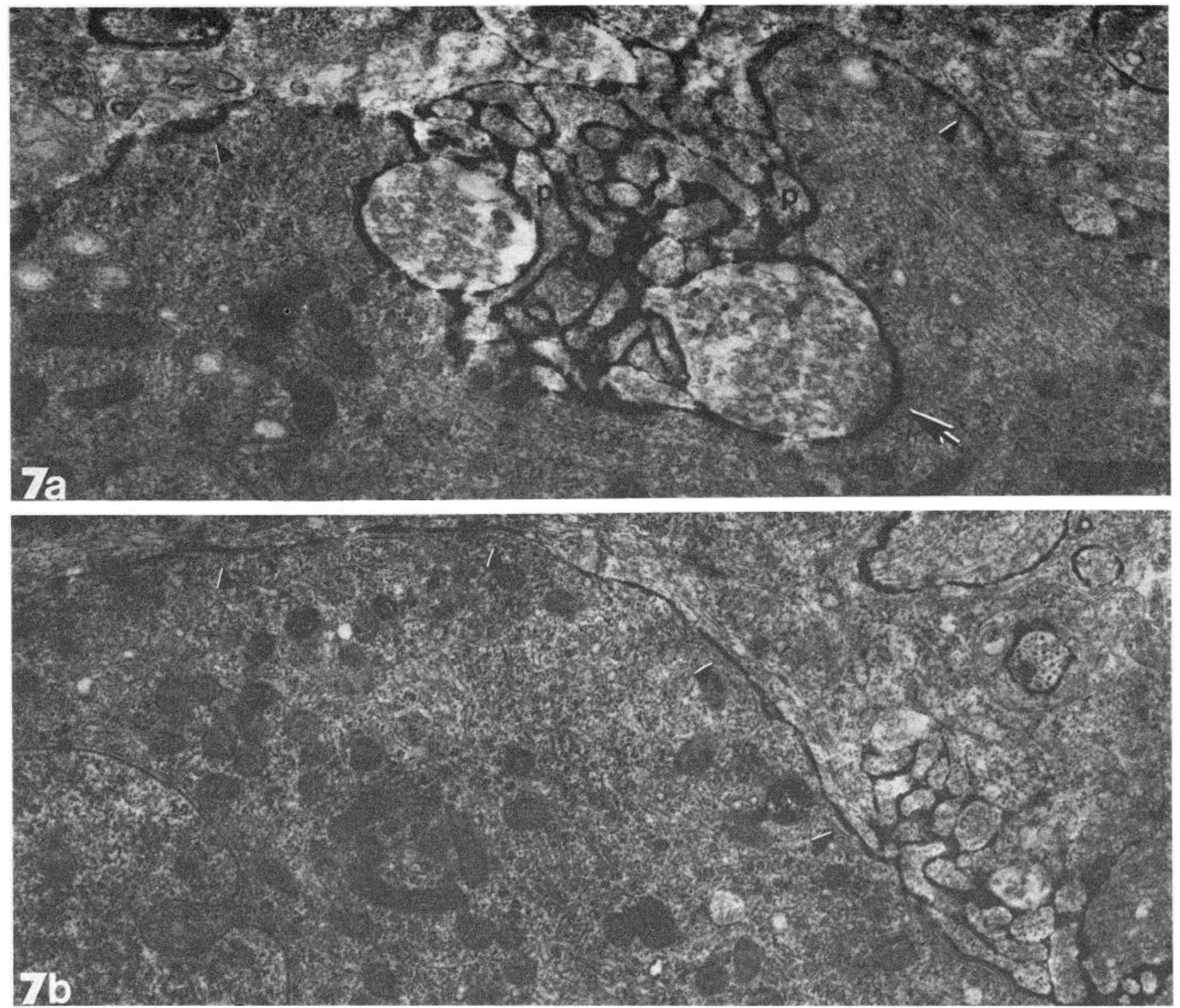

Figure 7. Accessibility of the entire neuronal surface membrane to an HRP-labeled monoclonal antibody to a neuronal surface membrane component. $a$, Dense reaction product fills the cleft of a synapse (arrow) on the soma of a 16-day-old chick embryo ciliary neuron following incubation in avian Ringer solution containing $20 \mu \mathrm{g} / \mathrm{ml}$ of HRP-labeled monoclonal antibody for $2 \mathrm{hr}$ at room temperature, rinsing for $2 \mathrm{hr}$ with several changes of avian Ringer solution, fixation, rinsing, and staining for peroxidase activity. The labeled synapse is characterized by an enhanced postsynaptic density, a widening of the cleft, and an accumulation of clear synaptic vesicles adjacent to the presynaptic membrane. The short processes $(p)$ and smooth surface membrane (arrowheads) in the vicinity of the reacted synapse are also heavily labeled. Magnification $\times 56,990$. $b$, The entire surface membrane (arrowheads) of a 16-day-old chick embryo ciliary neuron is labeled by the HRP-labeled monoclonal antibody. Magnification $\times 62,040$.

product similar to those lining the membrane of the short processes. No synapses were found to be heavily labeled by HRP-Bgt, while only a small fraction appeared to be lightly labeled. The vast majority of clearly identifiable synapses were unlabeled.

\section{Discussion}

The morphological criteria used here to identify chemical synapses on choroid and ciliary neurons commonly have been used in the past to distinguish synapses on these neurons (De Lorenzo, 1960; Hess, 1965; Landmesser and Pilar, 1972) as well as synapses on neurons in many other tissues (Peters et al., 1976). The only known chem- ical synaptic transmission to chick ciliary ganglion neurons is nicotinic cholinergic and gives rise to fast excitatory postsynaptic potentials (Martin and Pilar, 1963a). While the distribution of nicotinic ACh receptors on neurons has yet to be determined, it seems very likely that the receptors are most concentrated in the postsynaptic membrane. At the adult vertebrate neuromuscular junction, ACh receptors normally are tightly clustered at high density in the postsynaptic membrane and are almost nonexistent in the plasmalemma a few micrometers away (Miledi, 1960; Peper and McMahan, 1972; Fertuck and Salpeter, 1976). Electrophysiological studies on autonomic neurons have indicated that points of highest 


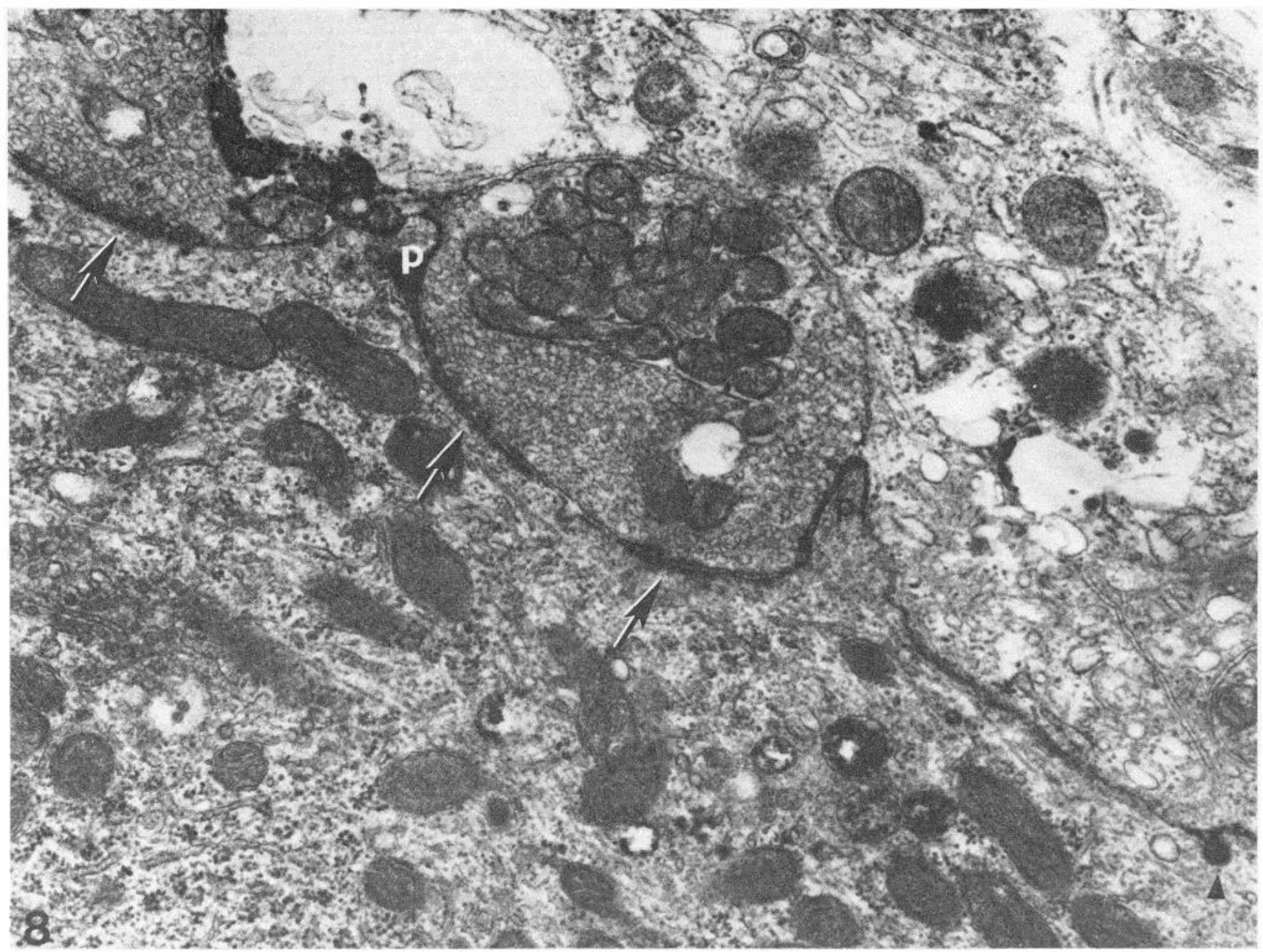

Figure 8. Absence of HRP-Bgt labeling at synapses of adult neurons. The pre- and postsynaptic membranes of synapses (arrows) on the soma of an 8-month-old chick ciliary neuron are not labeled following HRP-Bgt incubation and HRP reaction. The short processes $(p)$ immediately adjacent to the unreacted specialized synaptic zones are heavily labeled as are the surfaces of other nearby processes. A small invaginated region of the smooth surface membrane (arrowhead) of the soma is also labeled. Magnification $\times 71,820$.

ACh sensitivity correlate well with synaptic boutons (Harris et al., 1971; Roper, 1976), although it was not possible to determine the exact distribution of receptors with respect to the postsynaptic membrane.

The fact that nearly all of the HRP-Bgt labeling on chick ciliary ganglion neurons lay outside of synapses strongly suggests that the toxin binding site is different from the synaptic $\mathrm{ACh}$ receptor for these neurons. The few lightly labeled synapses found might reflect either a low level of $\alpha$-Bgt sites in some synapses or the translocation of small bits of reaction product from the heavily labeled membranes nearby. The general absence of label on synaptic membranes did not reflect a preferential loss of reaction product from synapses during processing of the tissue, nor did it reflect an inability of the HRP-Bgt to penetrate the synaptic cleft. An HRP-labeled monoclonal antibody which is considerably larger than the conjugated toxin was able to enter the cleft and heavily label the postsynaptic membrane in addition to most of the plasma membrane under identical labeling, washing, and fixing conditions.
The large amount of extrasynaptic HRP-Bgt labeling on the neurons was specific since it was completely blocked by $d$-tubocurarine and hexamethonium or by unlabeled $\alpha$-Bgt, and the amount of labeling was consistent with the expected number of high affinity $\alpha$-Bgt binding sites. Values for the number of such sites per neuron in adult ciliary ganglia range from $3 \times 10^{6}$ (Chiappinelli and Giacobini, 1978) to $9 \times 10^{6}$ (Gangitano et al., 1978). The total surface area for large adult ciliary neurons including short processes has been estimated at 16 $\times 10^{3} \mu \mathrm{m}^{2}$ (Cantino and Mugnaini, 1975). If the average neuronal diameter is about two-thirds that of the large ciliary cells, the mean surface area would be about $7 \times$ $10^{3} \mu \mathrm{m}^{2}$. Assuming that the labeled membrane constitutes a quarter of the total surface area suggests a site density of about $3 \times 10^{3} / \mu \mathrm{m}^{2}$. Comparable levels of labeling have been obtained when HRP-Bgt was reacted with muscle ACh receptors in young chick embryos (Jacob and Lentz, 1979) where receptor clusters have on the order of $10^{4}$ sites $/ \mu \mathrm{m}^{2}$ (Burden, 1977).

Might the high levels of extrasynaptic $\alpha$-Bgt binding 


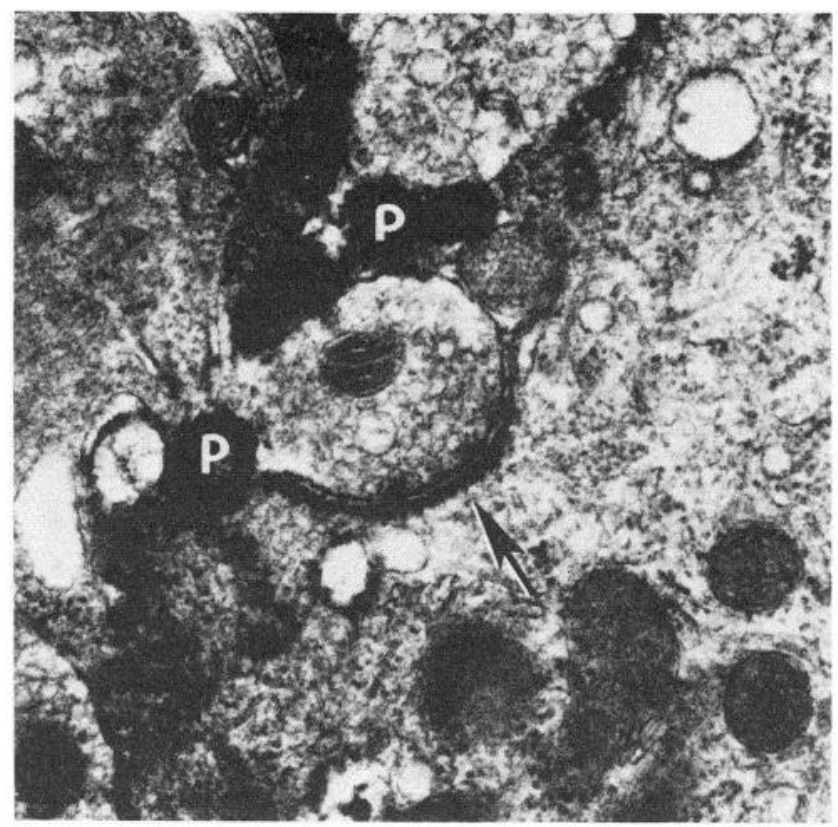

Figure 9. Proximity of labeled processes and unlabeled synapses. A synapse (arrow) on the soma of an 8-month-old chick ciliary neuron is not labeled, while the short processes $(p)$ emerging from the soma in the vicinity of the unreacted synapse are heavily labeled. Magnification $\times 79,350$. represent extrasynaptic nicotinic $\mathrm{ACh}$ receptors on the neurons? Unlike vertebrate skeletal muscle where $\alpha$-Bgt binds both to junctional and to extrajunctional nicotinic $\mathrm{ACh}$ receptors, it is possible that on ciliary ganglion neurons the toxin recognizes only the extrasynaptic receptor. If so, it would mean that extrasynaptic ACh receptors on adult ciliary ganglion neurons are present in much higher site densities than are their counterparts at the adult vertebrate neuromuscular junction (Miledi, 1960; Peper and McMahan, 1972; Fertuck and Salpeter, 1976). Also, although the pharmacology of the toxin binding is nicotinic, that is, it is blocked by $d$-tubocurarine, it should be recalled that the toxin is unable to inhibit the ACh sensitivity of ciliary ganglion neurons (Ravdin and Berg, 1979; Ravdin et al., 1981; Margiotta and Berg, 1982).

Could binding to synaptic ACh receptors be detected by the methods used here? The density of synaptic ACh receptors on ciliary ganglion neurons is unknown. Although the HRP-Bgt was active as judged by the high levels of specific extrasynaptic binding on ciliary ganglion neurons, the labeling of neuromuscular junctions, and the blockade of $\left[{ }^{125} \mathrm{I}\right] \alpha$-Bgt binding in chick skeletal myotube cultures (M. Smith and M. Jacob, unpublished observations), conjugate prepared by the procedures used here is known to have a lower apparent affinity for ACh receptors than does native $\alpha$-Bgt (Lentz et al., 1977; Jacob and Lentz, 1979). Accordingly, we cannot exclude

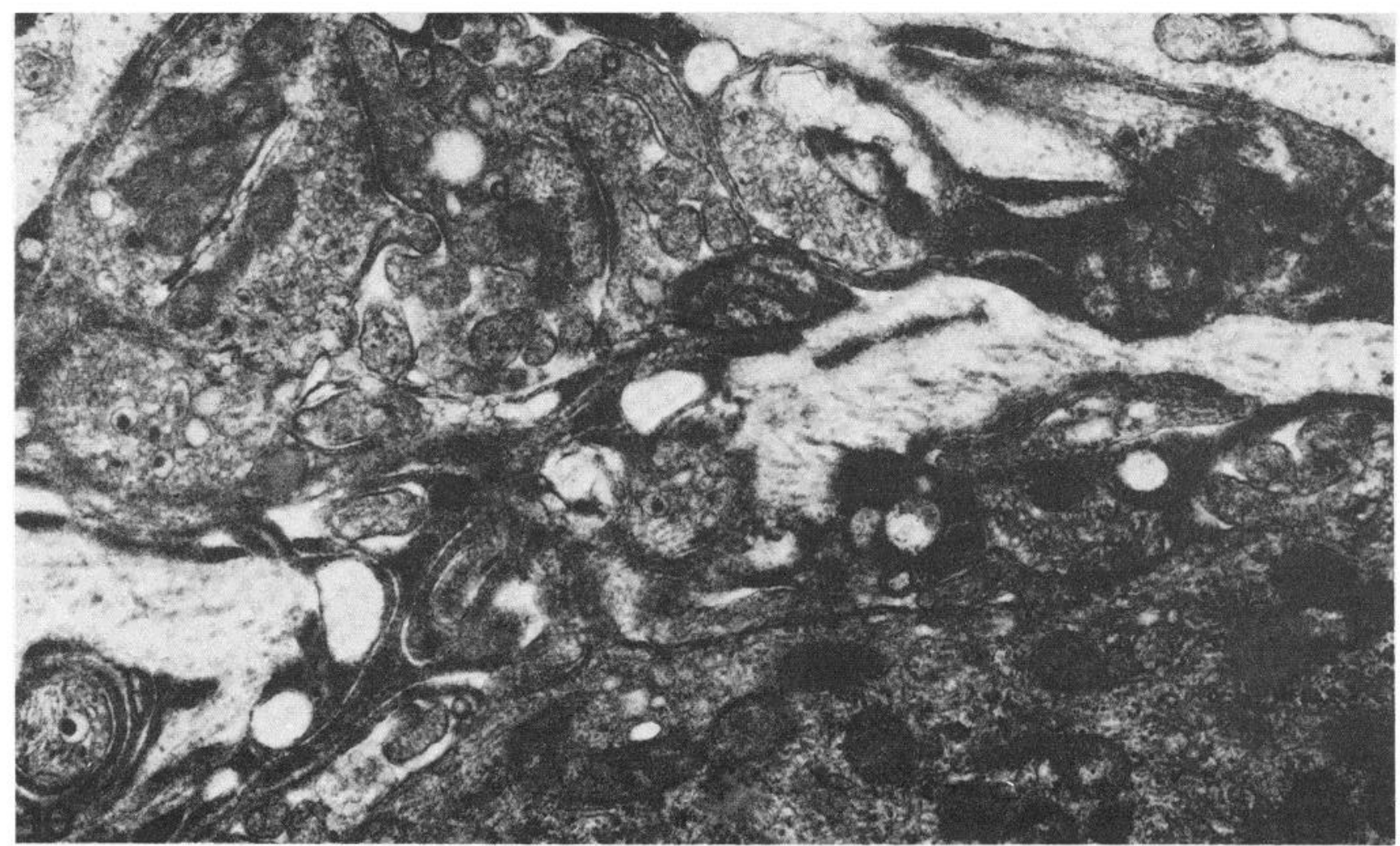

Figure 10. Specificity of HRP-Bgt binding to the adult neuron surface. The short processes $(p)$ and smooth surface membrane of the soma and dendrite $(d)$ of an 8-month-old chick ciliary neuron are not labeled following incubation in $100 \mu \mathrm{M} d$-tubocurarine and $1.4 \mathrm{~mm}$ hexamethonium prior to and along with $10^{-7} \mathrm{M}$ HRP-Bgt. Magnification $\times 69,260$. 
TABLE I

The number of unlabeled and lightly labeled synapses in developing and mature chick ciliary ganglion neurons ${ }^{a}$

\begin{tabular}{ccc}
\hline Age & $\begin{array}{c}\text { Number of } \\
\text { Unlabeled } \\
\text { Synapses }\end{array}$ & $\begin{array}{c}\text { Number of } \\
\text { Lightly } \\
\text { Labeled } \\
\text { Synapses }\end{array}$ \\
\hline 14-day-old embryo & 13 & 0 \\
16-day-old embryo & 42 & 2 \\
20-day-old embryo & 29 & 0 \\
8-month-old chick & 37 & 5 \\
Totals & 121 & 7 \\
\hline
\end{tabular}

${ }^{a}$ Determinations are based on the number of clearly identifiable synapses present on the surface of the HRP-Bgt-labeled cell population.

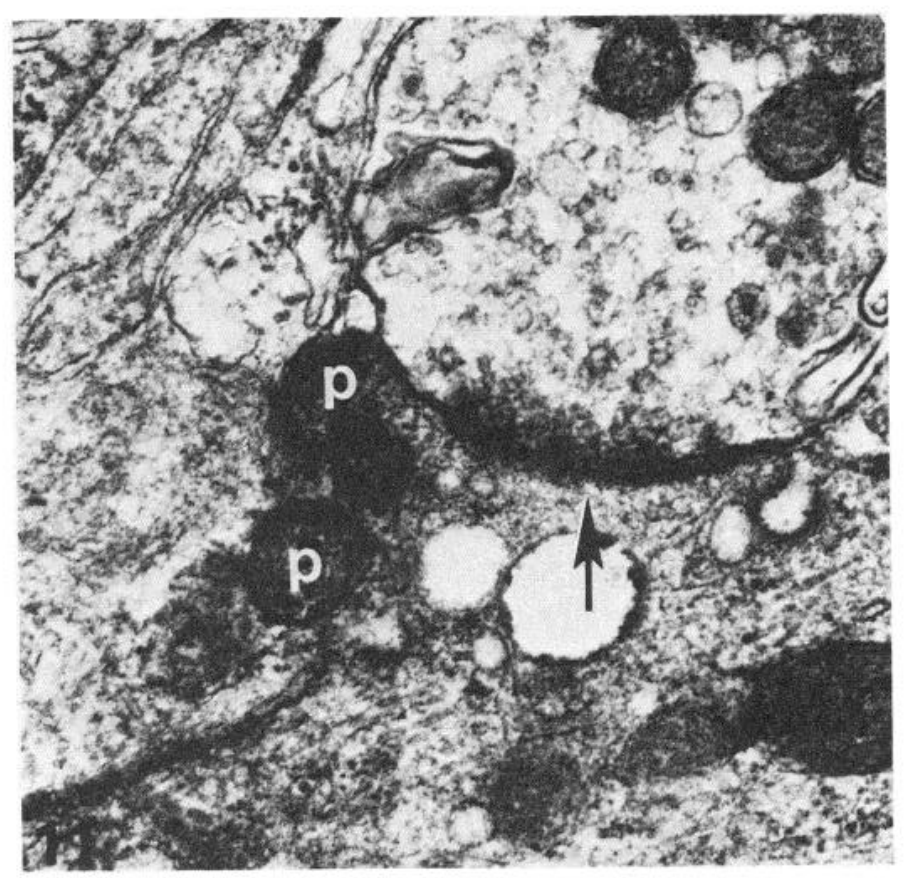

Figure 11. A lightly labeled synapse. A small number of globular deposits of reaction product are distributed irregularly within the cleft of a synapse (arrow) on the soma of an 8month-old chick ciliary neuron. Heavier, more uniform deposits of reaction product coat the surface membrane of short processes $(p)$ emerging from the soma in the immediate vicinity of the lightly labeled synapse. Magnification $\times 89,050$.

the possibility that synaptic receptors also bind the toxin but that the density of such sites is too low to detect with HRP-Bgt. If this were true, it would mean that synaptic receptors represent a very small fraction of the total high affinity binding sites on the neurons, even in the adult ganglion.

Cocchia and Fumagalli (1981) used an indirect immunocytochemical approach to examine the distribution of $\alpha$-Bgt binding sites on chick ciliary ganglion neurons at the ultrastructural level. In their studies ganglia were incubated with $\alpha$-Bgt, fixed, sectioned, and then exposed sequentially to rabbit anti- $\alpha$ Bgt antiserum, sheep antirabbit IgG antiserum, and peroxidase-antiperoxidase complex, and then stained for peroxidase activity. Their findings differed in several respects from those reported here. They found heavy labeling of synaptic membranes as well as extensive portions of plasma membrane away from synaptic areas. They also obtained labeling over satellite cell and preganglionic nerve terminal surfaces. The reasons for these differences are not clear. It is possible that the indirect labeling method using native $\alpha$-Bgt and amplifying the signal through successive antibody layers achieved a level of sensitivity that revealed $\alpha$-Bgt binding sites not detected by direct HRP-Bgt labeling. Alternatively, the indirect labeling method may have been less specific in this instance, allowing translocation of HRP reaction product.

A number of previous ultrastructural studies have suggested that $\alpha$-Bgt does bind to synaptic membranes in vertebrate neuronal tissue. Electron microscopic autoradiography with $\left[{ }^{125} \mathrm{I}\right] \alpha$-Bgt indicated binding at synaptic complexes in the hippocampal formation of rat brain (Hunt and Schmidt, 1978), in synaptic areas of the nucleus interpeduncularis and nucleus amygdaloideus medialis posterior of mouse brain (Arimatsu et al., 1978), and on dendritic processes of bipolar cells in the outer plexiform layer of goldfish retina (Schwartz and Bok, 1979). Electron microscopic examination of HRP-Bgt binding has revealed specific labeling of a small proportion of synapses in the inner plexiform layer of the chick retina (Vogel et al., 1977) and in the midbrain reticular formation and hypothalamic preoptic nucleus of rat brain as well as in a synaptosome preparation of whole rat brain (Lentz and Chester, 1977). HRP-Bgt has also been found to lightly label synaptic membranes on principal neurons in paravertebral sympathetic ganglia of the bullfrog, and in this case high concentrations of $\alpha$-Bgt have been shown to reversibly block $\mathrm{ACh}$ receptor function (Marshall, 1981). While in some instances the techniques used would not have discriminated between synaptic binding and binding to adjacent membrane regions, it is clear that in a number of cases specific toxin binding does occur to synaptic membranes.

Apparently, the properties of $\alpha$-Bgt binding sites on neurons can differ significantly among tissues and species. In addition to differences in the distribution of the sites and in their ability to affect $\mathrm{ACh}$ receptor function when saturated with $\alpha$-Bgt, the sites also appear to differ with respect to their immunological cross-reactivity with antisera produced against $\mathrm{ACh}$ receptors purified from electric tissue (Patrick and Stallcup, 1977a; Block and Billiar, 1979; Betz, 1981; Morley and Kemp, 1981; Norman et al., 1982) and may differ with respect to their subunit composition (Seto et al., 1981; Norman et al., 1982). It seems appropriate to think in terms of a family of $\alpha$-Bgt-binding components and that the components are capable of different functions in different neural tissues. Clearly, the presence of $\alpha$-Bgt binding sites on a class of neurons cannot be assumed to reflect $\mathrm{ACh}$ receptors until it is demonstrated directly.

The results presented here suggest that the $\alpha$-Bgt high affinity binding sites on chick ciliary ganglion neurons are different from the synaptic $\mathrm{ACh}$ receptors responsible for the excitatory postsynaptic potential. The function of the sites remains unknown. Their proximity to synaptic areas on the neurons implies a synaptic role. Possibly, 
the sites represent membrane components important for the formation or maintenance of synapses. Alternatively, the sites may represent receptors responding to $\mathrm{ACh}$ or some other ligand which influence synaptic function over a relatively slow time course and therefore do not need to be tightly clustered within the postsynaptic membrane.

\section{References}

Arimatsu, Y., A. Seto, and T. Amano (1978) Localization of $\alpha$ bungarotoxin binding sites in mouse brain by light and electron microscopic autoradiography. Brain Res. 147: 165-169.

Ascher, P., W. A. Large, and H. P. Rang (1979) Studies on the mechanism of action of acetylcholine antagonists on rat parasympathetic ganglion cells. J. Physiol. (Lond.) 295: 139-170.

Betz, H. (1981) Characterization of the $\alpha$-bungarotoxin receptor in chick embryo retina. Eur. J. Biochem. 117: 131-139.

Block, G. A., and R. B. Billiar (1979) Immunologic similarities between the hypothalamic $\alpha$-bungarotoxin receptor and the Torpedo californica nicotinic cholinergic receptor. Brain Res. 178: 381-387.

Brown, D. A., and L. Fumagalli (1977) Dissociation of $\alpha$-bungarotoxin binding and receptor block in the rat superior cervical ganglion. Brain Res. 129: 165-168.

Burden, S. (1977) Development of the neuromuscular junction in the chick embryo: The number, distribution, and stability of acetylcholine receptors. Dev. Biol. 57: 317-329.

Bursztajn, S., and M. D. Gershon (1977) Discrimination between nicotinic receptors in vertebrate ganglia and skeletal muscle by alpha-bungarotoxin and cobra venoms. J. Physiol. (Lond.) 269: 17-31.

Cantino, D., and E. Mugnaini (1975) The structural basis for electrotonic coupling in the avian ciliary ganglion. A study with thin sectioning and freeze-fracturing. J. Neurocytol. 4: 505-536.

Carbonetto, S. T., D. M. Fambrough, and K. J. Muller (1978) Non-equivalence of $\alpha$-bungarotoxin receptors and acetylcholine receptors in chick sympathetic neurons. Proc. Natl. Acad. Sci. U. S. A. 75: 1016-1020.

Chiappinelli, V. A., and E. Giacobini (1978) Time course of appearance of $\alpha$-bungarotoxin binding sites during development of chick ciliary ganglion and iris. Neurochem. Res. 3: 465-478.

Chiappinelli, V. A., J. B. Cohen, and R. E. Zigmond (1981) The effects of $\alpha$ - and $\beta$-neurotoxins from the venom of various snakes on transmission in autonomic ganglia. Brain Res. 211: 107-126.

Cocchia, D., and L. Fumagalli (1981) Immunocytochemical localization of $\alpha$-bungarotoxin receptors in the chick ciliary ganglion: Synaptic and extrasynaptic sites? Neurochem. Int. 3: $123-128$.

Cowan, W. M., and E. Wenger (1968) Degeneration in the nucleus of origin of the preganglionic fibers to the chick ciliary ganglion following early removal of the optic vesicle. J. Exp. Zool. 168: 105-124.

De Lorenzo, A. J. (1960) The fine structure of synapses in the ciliary ganglion of the chick. J. Biophys. Biochem. Cytol. 7: 31-36.

Duggan, A. W., J. G. Hall, and C. Y. Lee (1976) Alpha-bungarotoxin, cobra neurotoxin and excitation of Renshaw cells by acetylcholine. Brain Res. 107: 166-170.

Fertuck, H. C., and M. M. Salpeter (1976) Quantitation of junctional and extrajunctional acetylcholine receptors by electron microscope autoradiography after ${ }^{125} \mathrm{I}-\alpha$-bungarotoxin binding at mouse neuromuscular junctions. J. Cell Biol. 69: 144-158.

Fumagalli, L., G. DeRenzis, and N. Miani (1978) Alpha-bungarotoxin-acetylcholine receptors in the chick ciliary gan- glion: Effects of deafferentation and axotomy. Brain Res. 153: 87-98.

Gangitano, C., L. Fumagalli, G. DeRenzis, and C. O. Sangiacomo (1978) Alpha-bungarotoxin-acetylcholine receptors in the chick ciliary ganglion during development. Neuroscience 3: 1101-1108.

Ginsborg, B. L. (1960) Spontaneous activity in muscle fibres of the chick. J. Physiol. (Lond.) 150: 707-717.

Harris, A. J., S. W. Kuffler, and M. J. Dennis (1971) Differential chemosensitivity of synaptic and extrasynaptic areas on the neuronal surface membrane in parasympathetic neurons of the frog tested by microapplication of acetylcholine. Proc. $R$. Soc. Lond. (Biol.) 177: 541-553.

Hess, A. (1965) Developmental changes in the structure of the synapse on the myelinated cell bodies of the chicken ciliary ganglion. J. Cell Biol. 25: 1-19.

Hunt, S. P., and J. Schmidt (1978) The electron microscopic autoradiographic localization of $\alpha$-bungarotoxin binding sites within the central nervous system of the rat. Brain Res. 142: 152-159.

Jacoh, M., and T. I. I Lentz (1979) Localization of acetylcholine receptors by means of horseradish peroxidase- $\alpha$-bungarotoxin during formation and development of the neuromuscular junction in the chick embryo. J. Cell Biol. 82: 195-211.

Ko, C. P., H. Burton, and R. P. Bunge (1976) Synaptic transmission between rat spinal cord explants and dissociated superior cervical ganglion neurons in tissue culture. Brain Res. 117: 437-460.

Kouvelas, E. D., M. A. Dichter, and L. A. Greene (1978) Chick sympathetic neurons develop receptors for $\alpha$-bungarotoxin in vitro, but the toxin does not block nicotinic receptors. Brain Res. 154: 83-93.

Landmesser, L., and G. Pilar (1972) The onset and development of transmission in the chick ciliary ganglion. J. Physiol. (Lond.) 222: 691-713.

Landmesser, L., and G. Pilar (1974a) Synaptic transmission and cell death during normal ganglionic development. J. Physiol. (Lond.) 241: 737-749.

Landmesser, L., and G. Pilar (1974b) Synapse formation during embryogenesis on ganglion cells lacking a periphery. J. Physiol. (Lond.) 241: 715-736.

Landmesser, L., and G. Pilar (1978) Interactions between neurons and their targets during in vivo synaptogenesis. Fed. Proc. 37: 2016-2022.

Lentz, T. L., and J. Chester (1977) Localization of acetylcholine receptors in central synapses. J. Cell Biol. 75: 258-267.

Lentz, T. L., J. E. Mazurkiewicz, and J. Rosenthal (1977) Cytochemical localization of acetylcholine receptors at the neuromuscular junction by means of horseradish peroxidase labeled $\alpha$-bungarotoxin. Brain Res. 132: 423-442.

Margiotta, J. F., and D. K. Berg (1982) Functional synapses are established between ciliary ganglion neurones in dissociated cell culture. Nature 296: 152-154.

Marshall, L. M. (1981) Synaptic localization of $\alpha$-bungarotoxin binding which blocks nicotinic transmission at frog sympathetic neurons. Proc. Natl. Acad. Sci. U. S. A. 78: 1948-1952.

Marlin, A. R., and G. Pilar (1963a) Dual mode of synaptic transmission in the avian ciliary ganglion. J. Physiol. (Lond.) 168: 443-463.

Martin, A. R., and G. Pilar (1963b) Transmission through the ciliary ganglion of the chick. J. Physiol. (Lond.) 168: 464-475.

Miledi, R. (1960) The acetylcholine sensitivity of frog muscle fibres after complete or partial denervation. J. Physiol. (Lond.) 151: 1-23.

Morley, B. J., and G. E. Kemp (1981) Characterization of a putative nicotinic acetylcholine receptor in mammalian brain. Brain Res. Rev. 3: 81-104.

Nakane, P. K., and A. Kawaoi (1974) Peroxidase-labeled anti- 
body. A new method of conjugation. J. Histochem. Cytochem. 22: 1084-1091.

Norman, R. I., F. Mehraban, E. A. Barnard, and J. O. Dolly (1982) Nicotinic acetylcholine receptor from chick optic lobe. Proc. Natl. Acad. Sci. U. S. A. 79: 1321-1325.

Nurse, C. A., and P. H. O'Lague (1975) Formation of cholinergic synapses between dissociated sympathetic neurons and skeletal myotubes of the rat in cell culture. Proc. Natl. Acad. Sci. U. S. A. 72: 1955-1959.

Oswald, R. E., and J. A. Freeman (1981) Alpha-bungarotoxin binding and central nervous system nicotinic acetylcholine receptors. Neuroscience $6: 1-14$.

Patrick, J., and W. B. Stallcup (1977a) Immunological distinction between acetylcholine receptor and the $\alpha$-bungarotoxin binding component on sympathetic neurons. Proc. Natl. Acad. Sci. U. S. A. 74: 4689-4692.

Patrick, J., and W. B. Stallcup (1977b) $\alpha$-Bungarotoxin binding and cholinergic receptor function on a rat sympathetic nerve line. J. Biol. Chem. 252: 8629-8633.

Peper, K., and U. J. McMahan (1972) Distribution of acetylcholine receptors in the vicinity of nerve terminals on skeletal muscle of the frog. Proc. R. Soc. Lond. (Biol.) 181: 431-440.

Peters, A., S. L. Palay, and H. deF. Webster (1976) Synapses. In The Fine Structure of the Nervous System, pp. 118-180, W. B. Saunders Co., Philadelphia.
Ravdin, P. M., and D. K. Berg (1979) Inhibition of neuronal acetylcholine sensitivity by $\alpha$-toxins from Bungarus multicinctus venom. Proc. Natl. Acad. Sci. U. S. A. 76: 2072-2076.

Ravdin, P. M., R. M. Nitkin, and D. K. Berg (1981) Internalization of $\alpha$-bungarotoxin on neurons induced by a neurotoxin that blocks neuronal acetylcholine sensitivity. J. Neurosci. 1: 849-861.

Roper, S. (1976) The acetylcholine sensitivity of the surface membrane of multiply-innervated parasympathetic ganglion cells in the mudpuppy before and after partial denervation. J. Physiol. (Lond.) 254: 455-473.

Schwartz, I. R., and D. Bok (1979) Electron microscopic localization of $\left[{ }^{125} I\right] \alpha$-bungarotoxin binding sites in the outer plexiform layer of the goldfish retina. J. Neurocytol. 8: 53-66.

Seto, A., Y. Arimatsu, and T. Amano (1981) Subunit structure of $\alpha$-bungarotoxin binding component in mouse brain. J. Neurochem. 37: 210-216.

Syapin, P. J., P. M. Salvaterra, and J. K. Engelhardt (1982) Neuronal-like features of TE671 cells: Presence of a functional nicotinic cholinergic receptor. Brain Res. 231: 365-377.

Vogel, Z., G. J. Maloney, A. Ling, and M. P. Daniels (1977) Identification of synaptic acetylcholine receptor sites in retina with peroxidase-labeled $\alpha$-bungarotoxin. Proc. Natl. Acad. Sci. U. S. A. 74: 3268-3272. 